\title{
PENGARUH BENTUK DAN BERAT DALAM PERANCANGAN KAPAL BARANG CEPAT
}

\author{
Eko Julianto Sasono \\ Program Studi Diploma III Teknik Perkapalan \\ Universitas Diponegoro
}

\begin{abstract}
Eko Julianto Sasono, in this paper explain that cargo ship express represent the ship type developed and checked by Japan government in order to overcoming transportation problems by transport service in the land. Cargo ship express developed in two form, that is type of TSL-F and TSL-A. Determination form and ship weight express this very having an in with of speed and load capacity, in the plan laboured by a cargo ship express own the big cargo hold and light machine.
\end{abstract}

Keywords : Cargo ship express, load capacity, speed.

\section{PENDAHULUAN}

Tajamnya persaingan di bidang jasa angkutan barang terutama untuk barang-barang yang mempunyai nilai ekonomis tinggi menuntut adanya kecepatan dan ketepatan dalam penyampaiannya.Tuntutan ini seakan berlomba dengan sarana jalan yang tersedia, karena tidak sebandingnya perkembangan sarana jalan di satu sisi dan kenaikan jumlah kendaraan yang menggunakan sarana jalan tersebut disisi yang lain. Hal ini disebabkan antara lain oleh terbatasnya lahan untuk mengembangkannya (membuat jalan baru, melebarkan jalan yang ada).

Disamping itu polusi yang ditimbulkan oleh kendaraan itu sendiri juga menimbulkan permasalahan yang lain.Hal-hal tersebut telah mendasari usaha-usaha untuk membuat suatu sarana angkutan barang melalui laut. Pada saat ini sedang dikembangkan suatu jenis kapal barang cepat yang dapat menjawab semua permasalahan yang timbul diatas.

Kapal barang cepat yang dikembangkan tersebut penelitiannya sudah dilakukan sejak tahun 1989, kapal ini mempunyai kecepatan sekitar 50 knot atau kurang lebih $93 \mathrm{~km} / \mathrm{jam}$ berkapasitas angkut barang sebesar 1000 ton dengan jarak jelajah yang dapat dicapai yaitu 900 $\mathrm{km}$, sehingga jarak Jakarta - Surabaya akan dapat ditempuh hanya sekitar 10 jam perjalanan.

\section{DASAR TEORI \\ Pengertian}

Kapal cepat adalah kapal yang mempunyai range angka froude $0,3 \mathrm{~s} / \mathrm{d} 1,5$ atau kapal yang memiliki angka perbandingan V/VL . 1,0 - 5,0 Secara garis besar kapal cepat mempunyai 2 (dua) macam bentuk yaitu displacement hull (round bilge) dan planing hull (hard chine) dengan B (lebar garis air) serta LCB (letak titik tekan terhadap midship) yang bervariasi, diperoleh performance kapal yang berbeda-beda. Demikian juga pemasangan Spray rall dan transom wedge sangat menentukan performance kapal.
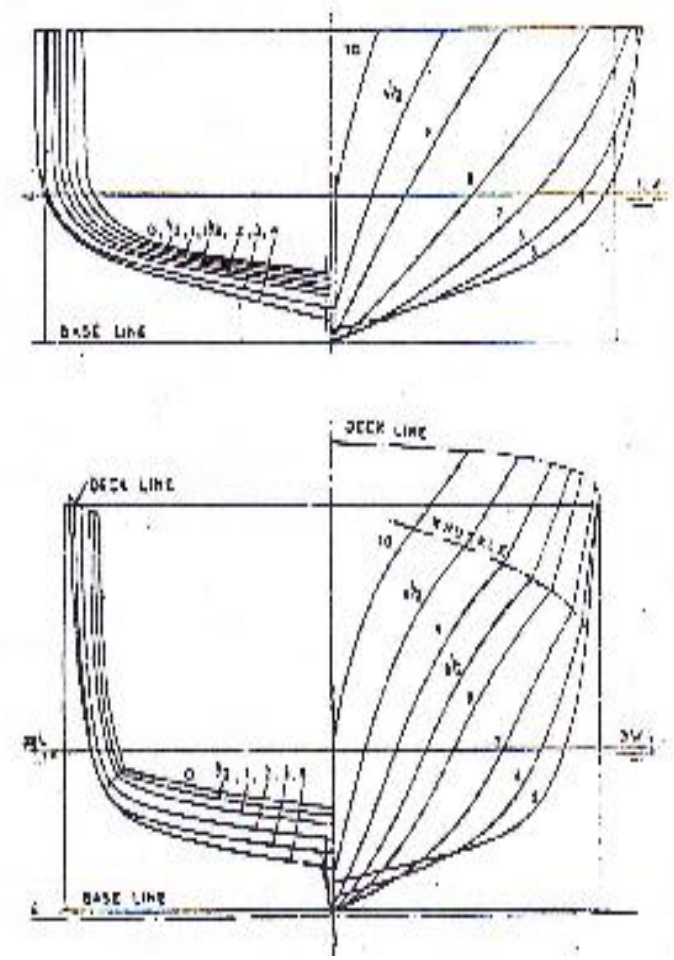

Gambar 1. Characteristic Section of Roud Bilge Hull

Pada kapal cepat mempunyai 2 (dua) type bentuk badan kapal yakni displacement hull dan planing hull. Pada kapal tipe displacement hull mempunyai bentuk lengkung pada daerah bilge dengan bentuk butlock line dan water line yang mendekati lurus serta mempunyai transom, sehingga biasa juga disebut sebagai tipe round bilge, seperti terlihat dalam gambar 1. Kapal tipe planing hull juga disebut tipe hard chine pada kecepatan tinggi akan mengalami extra dynamic lift. Kapal tipe ini 
mempunyai bentuk bottom yang flat dengan deadrise yang konstan atau berubah pada bagian belakang kapal seperti terlihat pada gambar 2 . Kapal kapal tipe round bilge banyak digunakan untuk work boat, frigate dan covertte field, sedangkan kapal tipe hard chine sering dibangun untuk kapal-kapal yang mempunyai kecepatan relatif rendah, sebab bentuk badan kapal ini memungkinkan dibangun lebih mudah dan murah. Ditinjau dari tahanannya, round bilge hull lebih kecil dari hard chine tetapi untuk memperoleh performance yang baik dan cenderung memilih hard chine hull. Hard chine hull (planing hull) merupakan pilihaan terbaik. Untuk kapal dengan kecepatan tinggi, terbukti telah banyak patroli craft yang dibangun dengan panjang $100 \mathrm{ft}$, mampu berlayar dengan kecepatan 60 knot.

\section{Parameter Bentuk badan Kapal}

Ukuran utama optimum sebuah kapal yang direncanakan tidak mungkin diperoleh hanya dengan analisa saja, tetapi dari data hasil percobaan-percobaan model di laboratorium hydrodinamika.

Dengan memperlakukan model-model tersebut akan diperoleh ukuran utama optimum yang lengkap dengan karakteristiknya sesuai dengan kondisi pelayaran yang mungkin akan dialaminya. Dalam pembuatan model percobaan di laboratorium urntuk sebuah displacement perlu ditentukan suatu harga patokan yang tetap, misalnya panjang (L) tetap, atau lebar (B) tetap, kernudian ukuran utama yang lain divariasi. Apabila ditentukan panjang kapal Lwl tetap, dari hasil percobaan bahwa performance kapal dipengaruhi oleh 2 parameter sebagai berikut :

- Lebar Garis Air (Drag)

Lift dan drag untuk sebuah papan merupakan fungsi dari effective planing angle dan karakteristik yang berkaitan dengan perbandingan antara lebar dengan panjang yang sering juga disebut aspect ratio dan dapat juga berlaku untuk sebuah kapal, dengan rumus Newton, tahanan untuk papan dapat dihitung sebagai berikut :

$\mathrm{R}=\mathrm{K} . \mathrm{A} . \mathrm{P} . \mathrm{V} 2$

Keterangan:

$\mathrm{R}=$ Tahanan

$\mathrm{K}=$ Konstanta untuk papan

$\mathrm{A}=$ Luas permukaanbalah

= Density (kerapatan massa air)

$\mathrm{V}=$ Keeepatan

Sedangkan untuk kapal Froude memberikan rumus pendekatan $R$. f.A.P.V2, dimana $f=$ konstant yang nantinya akan diperoleh dari hasil percobaan. Untuk kapal dengan kecepatan tinggi harga tahanan gesek dari permukaan badan kapal yang tercelup akan lebih besar dari tahanan tahanan lain, dimana harga tahanan gelombang dapat diperkecil dengan menambahkan steeper plahe angle pada konstruksi bottom kapal. Planing angle yang normal bertambah secara teratur mulai dari 1 (satu) derajat untuk B/L (aspect ratio) $=2$ sampai lebih dari 4 derajat untuk aspect ratio $=6$.
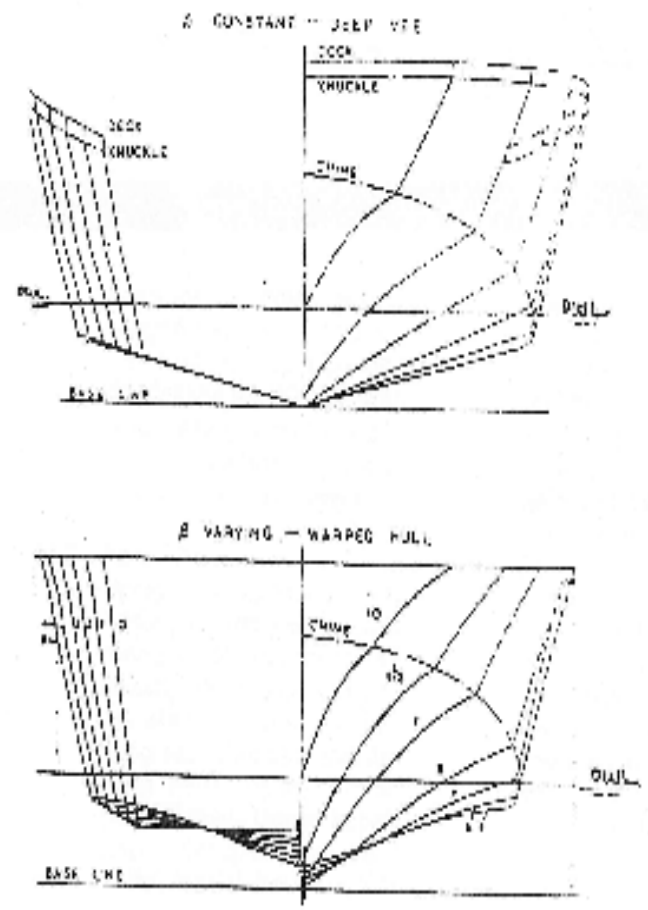

Gambar 2. Characteristic Section of Hard Chine Hulls

- $\quad$ Letak titik Tekan (LCB)

Letak titik tekan (Lcb) Pergeseran titik berat ini, merupakan salah satu hal yang membedakan kapal kecil dengan kapal besar. Pada kapal besar letak titik berat garis air CF hampir sama dengan letak titik tekan CB, sedangkan pada kapal kecil (planing type), titik berat garis air $\mathrm{CF}$ lebih jauh kebelakang dibandingkan dengan titik tekan CB kapal tersebut. Pada kapal-kapal type planing hull sering kali titik berat garis air CF berada sampai 15\% L dibelakang midship (pada saat diam). Letak titik CF ini akan selalu berubah secara longitudinal sesuai perubahan bentuk bldang garis air tergantung keadaan sarat kapal pada saat berlayar dan perubahan $\mathrm{CF}$ tersebut dengan sendirinya selalu berkaitan oleh perubahan titik tekan CB. Perubahan letak tltik tekan CB inl tidak hanya statis mengikuti kondisi sarat kapal, tetapi Juga disebabkan adanya dynamic pressure. Walaupun perubahan letak titik tekan ini sulit untuk 
diukur tetapi dalam keadaan statis, perencana dapat mencoba dengan model-modelnya untuk membuat variasi letik titik tekan statis dalam kaitannya dengan performace kapal

\section{Cara Memperbaiki Performance Kapal}

Dalarn proses pembuatan sebuah kapal mungkin akan dialami penyimpanganpenyimpangan, sehingga tidak sesuai lagi dengan apa yang diharapkan dalam design. Untuk memperbaiki kekurangan yang berkaitan dengan kecepatan dan effective power yang dibutuhkan untuk mendorong kapal dapat dilakukan dengan cara sebagai berikut:

- $\quad$ Transom wedge atau flap.

Apabila sebuah kapal bergerak dengan kecepatan tinggi sehingga cukup mengalami dynamic lift, maka kapal akan mempunyai performance yang terbaik apabila kapal tersebut bergerak pada kondisi trim angle yang optimum.

Telah banyak kapal-kapal yang direncanakan untuk dapat mencapai keadaan terbaiknya dengan menambahkan wedge atau flap pada transom kapal tersebut. Pada kecepatan yang direncanakan hydrodinamic force akan mengubah natural running dari kapal. Supaya panjang kapal tidak berubah maka transom wedge dipasang rata dengan transom. Berdasarkan hasil penelitian diperoleh ketentuan bahwa pemasangan transom wedge hanya diperbolehkan mempunyai kemiringan sampai 4 derajat dibawah bottom dengan lebar sama dengan tronsom dan panjangnya 1-2\% dari panjang kapal. Pada paling craft, pemasangan flap lebih disukai dari wedge. Flap dipasang dibelakang tronsom dengan lebar yang sama dengan tronsom karena lebih muda mengatur sudutnya.

\section{- Spray Rail}

Spray rail dipasang pada bagian haluan kapal untuk mengontrol membesarnya gelombang haluan yang tipis atau pancaran air tipis yang berhubungan erat dengan bertambahnya kecepatan kapal. Untuk kapal-kapal dengan tipe hard chain, posisi bow knuckle merupakan tempat pemasangan spray rail yang paling baik dan membujur kedepan dikelilingi haluan.

Pada kapal-kapal tipe round bilge gelombang haluan akan mudah naik mendekati geladak, terutama pada saat angin bertiup dari arah samping kapal, pancaran air akan membumbung keatas kapal secara terus menerus. Dengan memasang spray rail maka pancaran air tersebut dapat dibelokkan (dijatuhkan sebelum mengenai geladak); Lebih dari itu pada kecepatan yang tinggi, tahanan kapal akan berkurang dengan terangkatnya bagian haluan kapal oleh tekanan air yang mengenai bagian bawah dari rail. Ukuran dan penempatannya bukan merupakan suatu hal yang mengikat, hanya dianjurkan memasang spray rail lebih dari setengah panjang. Sisi bawah dari rail dibuat sejajar dengan permukaan air pada saat air tenang.

\section{MENENTUKAN BENTUK DAN BAHAN KAPAL}

Pengembangan dan penelitian kapal barang cepat tersebut dilakukan oleh salah satu negara raksasa dibidang perkapalan dunia saat ini yaitu Jepang. Penelitian yang dilakukan oleh pemerintah Jepang itu dibantu sepenuhnya oleh para industri galangan kapal raksasa di Jepang antara Iain Ishikawajima Heavy Industries, Sumitomo dan lain-lain. Hasil dari penelitian seperti yang dipublikasikan pada majalah shipbuilding International '94 telah mendapatkan 2 bentuk kapal barang cepat yaitu kapal barang cepat tipe TSL - F dan TSL - A (TSL adalah singkatan dari Techno Superliner).

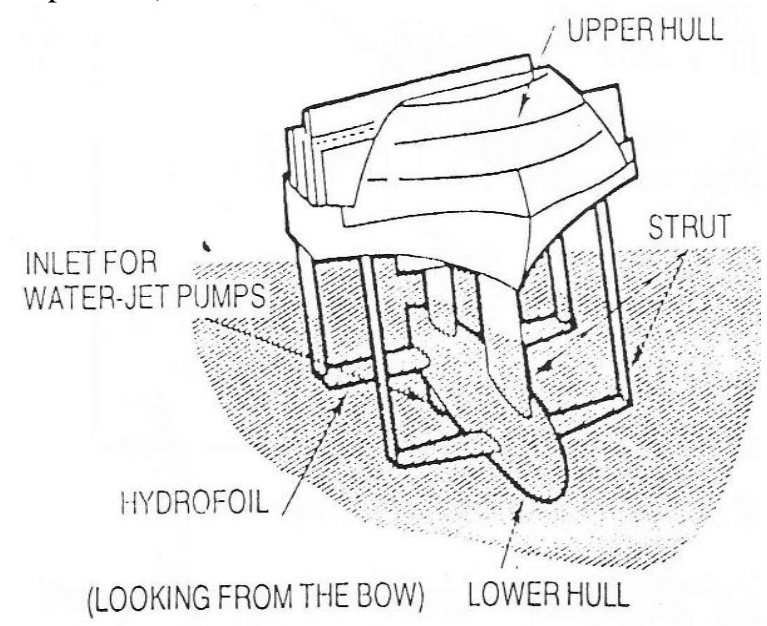

Gambar 3. kapal barang cepat type TSL - F

Ukuran utama dari salah satu tipe kapal barang cepat diatas yaitutipe TSL - A adalah sebagai berikut

$\begin{array}{lll}\text { - Panjang } & 127 & \mathrm{~m} \\ \text { - Lebar } & 27,2 & \mathrm{~m} \\ \text { - Tinggi } & 11,0 & \mathrm{~m} \\ \text { - Sarat } & & \end{array}$

- Sarat Pada saat berlabuh $\quad 5,0 \quad \mathrm{~m}$ Pada saat berlayar $\quad 1,4 \quad \mathrm{~m}$

- Kecepatan max. $\quad 50 \quad$ Knot

- Kapasitas angkut 1000 Ton

- Kapasitas motor penggerak 4 x 25000 PS (GT Turbin Gas)

- Propulsi water jet. 


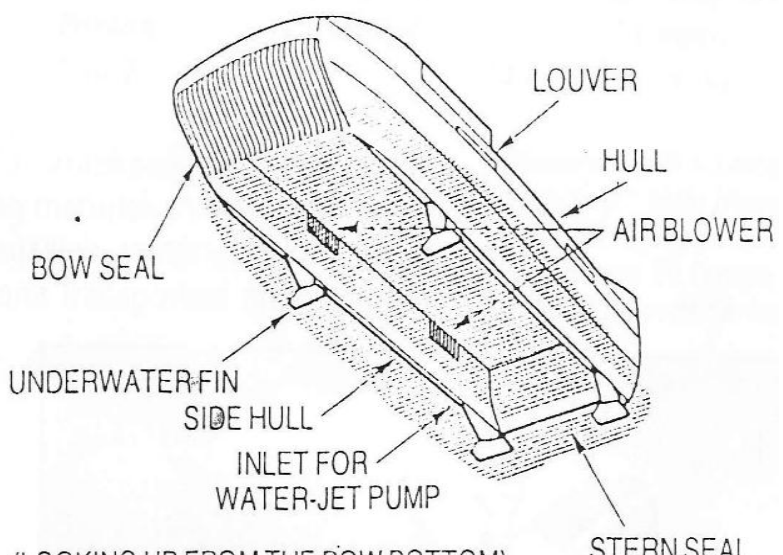

(LOOKING UP FROM THE BOW BOTTOM)

;

Gambar 4. kapal barang cepat type TSL-A

Penentuan bentuk dan bahan lambung kapal barang cepat ini menjadi sedemikian pentingnya karena erat kaitannya dengan, kecepatan tinggi yang hendak dicapai disamping kapasitas angkut barang yang dapat diangkut. Dari beberapa percobaan yang dilakukan terhadap model kapal, akhirnya dipilih bahan lambung kapal terbuat dari Allumunium alloy sedang untuk bagian-bagian konstruksi kapal yang terletak dibawah permukaan air digunakan bahan pelat baja tahan karat. Pemilihan bahan baja tahan karat lebih disebabkan untuk mengantisipasi adanya gaya hidrodinamis dan kavitasi

\section{MENENTUKAN BERAT KAPAL}

Penentuan berat kapal yang ideal juga sangat erat kaitannya dengan pemilihan jenis mesin yang digunakan nantinya. Untuk mengurangi berat permesinan maka dipergunakan mesin penggerak dari jenis turbin gas, karena disamping untuk mengurangi berat mesin penggunaan mesin jenis turbin gas ini juga mengandung maksud untuk mengeliminir tahanan hidrodinamis yang disebabkan oleh adanya poros baling-baling penyangga poros baling-baling dan kemudi. Turbin gas yang digunakan pada kapal ini akan menggerakkan sistim propulsi water jet dan dalam pengembangannya yang seirama dengan mesin-mesin yang digunakan pada pesawat terbang telah menyebabkan dipasangnya sistim propulsi yang menggunakan multy water jet dengan tenaga sebesar 20.000 - 25.000 daya kuda.

\section{PENUTUP}

Program pengembangan kapal barang cepat ini telah selesai dilakukan. Langkah-langkah akhir yang dewasa ini sudah digarap adalah pembuatan model kapal dengan skala 1 : 1 . Dua model kapal barang cepat masing-masing dari tipe TSL - F dan TSL - A sudah diselesaikan pembangunannya dan sudah dilakukan percobaan berlayar pada tahun 1994.

Perbandingan ukuran utama dari kedua model kapal barang cepat tersebut ditunjukkan pada Tabel 1.

Tabel 1. Perbandingan ukuran utama model kapal cepat

\begin{tabular}{|c|c|c|}
\hline & Type TSL - F & Type TSL - A \\
\hline Panjang & $17,1 \mathrm{~m}$ & $70,0 \mathrm{~m}$ \\
\hline Lebar & $6,2 \mathrm{~m}$ & $18,6 \mathrm{~m}$ \\
\hline Tinggi & $1,5 \mathrm{~m}$ & $7,5 \mathrm{~m}$ \\
\hline $\begin{array}{l}\text { Sarat air } \\
\text { (hull-borne) }\end{array}$ & $3,6 \mathrm{~m}$ & $\begin{array}{l}3,5 \mathrm{~m} \\
\text { (off-cushion) }\end{array}$ \\
\hline (foil-borne) & $2,1 \mathrm{~m}$ & $\begin{array}{l}1,1 \mathrm{~m} \\
\text { (on-cushion) }\end{array}$ \\
\hline $\begin{array}{l}\text { Kecepatan } \\
\text { (max.) }\end{array}$ & 40 knots & 50 knots \\
\hline Motor induk & $\begin{array}{l}1 \times 3800 \text { Ps } \\
(\mathrm{GT})\end{array}$ & $\begin{array}{l}2 \times 16000 \text { Ps } \\
(\mathrm{GT})\end{array}$ \\
\hline Propulsi & $1 \mathrm{x}$ water jet & $2 \mathrm{x}$ water jet \\
\hline Lain-lain & $\begin{array}{l}4 \times 2000 \text { Ps } \\
\text { lift fan }\end{array}$ & $\begin{array}{l}4 \times 2000 \text { Ps } \\
\text { lift fan }\end{array}$ \\
\hline
\end{tabular}

Diharapkan kapal barang cepat yang merupakan terobosan untuk menjawab tantangan kebutuhan sarana transportasi angkutan barang ini dapat dijadikan alternatif sarana transportasi laut saat ini.

\section{DAFTAR PUSTAKA}

1. BKI, 2001, Rules For Hull Construction, Volume II, PT. BKI (Persero), Jakarta

2. D. Balley, 1974, Performance Prediction-Fast Craft, Ship Division, NPL

3. Fakultas Teknik Perkapalan ITS, 1982, Diktat Rencana Garis , FT. Perkapalan ITS, Surabaya

4. Lindsay Lord, 1963, Naval Architecture of Planing Hulls, Cornell Maritime Press, Inc.

5. Ruddianto, MT, 2000, Perencanaan Kapal Jurusan Teknik Bangunan Kapal, Politeknik Perkapalan ITS, Surabaya

6. Storch, RL, Hommon, C Paud Bunch, HM, 1988, Ship production, Cornell Maritime Press, Maryland

7. Robert B Zubaly, 1996, Aplied Naval Architecture, Cornell Maritime Press, Centreville, Maryland 